\title{
Scramjet Development Tests Supporting the Mach 10 Flight of the X-43
}

\author{
R. C. Rogers ${ }^{*}$, A. T. Shih ${ }^{\dagger}$, and N. E. Hass ${ }^{\ddagger}$ \\ NASA Langley Research Center, Hampton, Virginia, 23681 USA
}

\begin{abstract}
The Hyper-X Project's successful third flight of the X-43 at near Mach 10 in 2004 proved the potential for airbreathing propulsion at hypersonic speeds. The engine flowpath used in the $X-43$ research vehicle was developed and evaluated in a systematic series of ground tests in the NASA HyPulse Shock Tunnel at conditions duplicating Mach 10 flight using a full scale height, partial width engine model of the flight engine. Tests were conducted over a range of equivalence ratios from 0.8 to 1.6 using hydrogen and a mixture of two-percent silane in hydrogen fuels. Silane gas was used as an ignition aid during the short duration of the pulse facility tests. Variation of the engine inflow conditions, pressure, temperature, and Mach number, were parametrically varied during the test entries to broaden the database over the expected uncertainty in the flight conditions. A review of the ground test technique and comparisons of the ground test pressures along with selected flight data are presented.
\end{abstract}

\section{Nomenclature}

Area

Enthalpy

Mach number

Pressure

$\mathrm{Q}, \mathrm{q} \quad$ Dynamic pressure

$\mathrm{R} \quad$ Radial coordinate

T Temperature

Us Shock speed

V Velocity

$\alpha \quad$ Angle of attack

$\phi \quad$ Equivalence ratio

\section{Subscripts:}

$1 \quad$ Facility test gas initial state

$5 \quad$ Shock tube end condition

cj Chapman-Jouget condition

cle Cowl leading edge

ne Nozzle exit

pit pitot pressure

pln plenum pressure

$\mathrm{t} \quad$ Stagnation condition

inf, $\infty \quad$ Flight condition

\footnotetext{
${ }^{*}$ Aerospace Engineer, Hypersonic Airbreathing Propulsion Branch, RTD, NASA Langley; Associate Fellow, AIAA

${ }^{\dagger}$ Aerospace Engineer, Hypersonic Airbreathing Propulsion Branch, RTD, NASA Langley; Member AIAA

* Aerospace Engineer, Hypersonic Airbreathing Propulsion Branch, RTD, NASA Langley; Member AIAA 
Acronyms and Abbreviations:

$\begin{array}{ll}\text { AR } & \text { Nozzle area ratio } \\ \text { CL } & \text { Centerline } \\ \text { CFD } & \text { Computational Fluid Dynamics } \\ \text { CLE } & \text { Cowl leading edge } \\ \text { CTE } & \text { Cowl trailing edge } \\ \text { DAS } & \text { Data Acquisition System } \\ \text { ER } & \text { Equivalence ratio } \\ \text { FB } & \text { Forebody } \\ \text { FBLE } & \text { Forebody leading edge } \\ \text { HSM } & \text { HyPulse Scramjet Model } \\ \text { HXRV } & \text { Hyper-X Research Vehicle } \\ \text { HyPulse } & \text { Hypersonic Pulse facility } \\ \text { LaRC } & \text { Langley Research Center } \\ \text { M10-KL8 } & \text { Mach 10, Keel Line 8 engine flowpath designation } \\ \text { RST } & \text { Reflected-Shock Tunnel } \\ \text { RV-F3 } & \text { Research Vehicle, flight 3 } \\ \text { SET } & \text { Shock-Expansion Tunnel } \\ \text { SFM } & \text { Silane-hydrogen Fuel Mixture } \\ \text { X-43 } & \text { Hyper-X Research Vehicle }\end{array}$

\section{Introduction}

The development of a scramjet engine flowpath concept for operation across the Mach 6 to 15 flight regime has been pursued for more than 30 years. ${ }^{1-3}$ Most recently, the Hyper-X Program ${ }^{4}$ has conducted an orderly series of ground tests in facilities that duplicate flight enthalpy at Mach 7 and 10 to support the atmospheric launch of an airframe-integrated scramjet engine research vehicle in flight tests. One objective of these ground tests was to aid the establishment of a scramjet engine-operation database at Mach 10 that would guide the design of the flight engine. In addition, the ground test program at Mach 10 was expected to provide confidence in the design and analysis computational tools and techniques. Such a database, when combined with the broad scramjet knowledge at and below flight Mach 7 conditions, has provided scramjet operational experience into the hypervelocity range. The two successful flights of the Hyper-X Research Vehicle (HXRV), also designated the X-43, at Mach 7 in March 2004 and again at Mach 10 in November 2004, have delivered flight data for an airframe-integrated scramjet engine concept that can be compared with ground test data to evaluate and confirm scramjet engine flowpath design and analysis tools.

The Hyper-X Mach 10 scramjet flowpath development and evaluation testing was performed primarily in the NASA HyPulse Shock Tunnel operating in the reflected-shock tunnel (RST) configuration at conditions that duplicated nominal Mach 10 flight speeds. ${ }^{5}$ This shock tunnel has a shock-induced detonation driver and delivers a test gas of shock-heated air at stagnation conditions of $3740 \mathrm{~K}$ and up to $30 \mathrm{MPa}$, with a useful steady test period of up to $3 \mathrm{~ms}$. The axisymmetric contoured facility nozzle expands the test gas flow through an area ratio of 225 to an exit diameter of about $67 \mathrm{~cm}$, of which about $40 \mathrm{~cm}$ is a uniform core flow at the nominal Mach 10 test condition.

The test series for the HXRV Mach 10 scramjet engine flowpath began in mid-year 1999 and progressed through late in 2000 with three test entries of a model of the scramjet flowpath design, which was designated Keel Line 6. These test series (identified as entries 3, 4, and 5) helped in the development of the test technique for acquiring scramjet data in a pulse facility. The outcome and results of the data from these three test entries led to changes to the engine flowpath to enhance performance and operational characteristics. The new engine flowpath, designated Keel Line 8, was tested from mid-year 2001 through early 2003 in test entries 7 and 8 . Keel Line 8 was the internal flowpath design that flew on the third flight of the HXRV in November 2004. The test hardware used in all tests in HyPulse, referred to as the HyPulse Scramjet Model (HSM), was a partial-width replica of the Hyper-X research vehicle that extended from about mid-length of the research vehicle forebody and included a portion of the nozzle expansion ramp.

The paper will present an overview of the scramjet testing of the HXRV Mach 10 flowpath in the HyPulse reflected-shock tunnel, including facility operation and calibration, model limitations, test technique and rationale, and some preliminary comparisons of the ground test results to the data acquired in flight. The ground test data comparisons are taken from test entry 8 , which was a series of engine flowpath evaluation tests. 


\section{Test Simulation and Conduct}

\section{A. Ground Test Simulation Method}

The typical approach used in ground test facilities to replicate scramjet engine inflow conditions expected in flight is depicted schematically in Figure 1. The concept is to build a test article that models a portion of the engine flowpath and conduct tests of the model at conditions that duplicate the stagnation enthalpy, and match flow profiles of static pressure and Mach number at the cowl entrance plane expected in flight. In the upper part of Figure 1, a sketch of the underside of the Hyper-X research vehicle (HXRV) is shown. The shaded region indicates the partial width and truncated length segment of the HyPulse Scramjet Model (HSM) hardware. The side view sketch (in the center of the figure) schematically illustrates the HXRV forebody shock system and the location of the HSM forebody leading edge at the start of the first forebody ramp on the HXRV. In the ground test, the rationale is to match the flight flowpath values of $\mathrm{M}, \mathrm{P}$, and $\mathrm{H}_{\mathrm{t}}$ at the entrance to the test hardware. The stagnation enthalpy is duplicated during facility operation and local Mach number is obtained by facility nozzle design and by the model mounting angle. However, facility pressure limitations constrain the simulated flight dynamic pressure capability. To compensate for the lower pressure, tests are conducted with higher model mounting angles that yield higher inflow pressures but lower Mach numbers. The generated conditions at the HSM cowl-leading edge (CLE) were varied by changes in facility conditions and model orientation. Additional description of the HSM hardware is presented in a later section.

\section{B. HyPulse Test Facility}

\section{Description}

The NASA HyPulse shock tunnel facility, shown schematically in Figure 2, is a dual-mode pulse facility that is configurable as a reflected-shock tunnel (RST) or a shock-expansion tunnel (SET). The shock tunnel is located at and operated by ATK-GASL, Inc., under contract to NASA. In the RST mode stagnation enthalpies in the test gas corresponding to flight speeds from Mach 5 to 10+ are achievable. In the SET mode stagnation enthalpies in the test gas corresponding to flight speeds from Mach 12 to near orbital are obtainable. The major components of the facility are: the driver, which is either cold helium at high-pressure (up to $98 \mathrm{MPa}$ or 14,200 psi), or a shock-induced detonation wave in a stoichiometric hydrogen-oxygen mixture diluted with argon (for RST) or helium (for SET); a shock tube section that is about $22 \mathrm{~m}(72 \mathrm{ft})$ long and $15 \mathrm{~cm}(6-\mathrm{in}$.$) diameter; and a test chamber 6.1 \mathrm{~m}(20-\mathrm{ft})$ long by $2.13 \mathrm{~m}$ (7-ft) diameter. An upstream portion of the shock tube section is used as the detonation driver for test conditions above flight Mach 7 enthalpy duplication. A downstream section of the shock tube is used as the acceleration tube in the SET mode. Additional information about HyPulse is presented in reference 5.

\section{Data systems}

The HyPulse data acquisition system (DAS) includes a cluster of digital oscilloscopes to acquire data with piezoelectric quartz-crystal pressure transducers and thin-film thermocouple heat-flux gages. The pressure sensors have $500 \mathrm{kHz}$ frequency response and sensitivities ranging from 1 to $100 \mathrm{mV} / \mathrm{psi}$, with a measurement uncertainty of less than $5 \%$ of full scale. Heat flux gages are platinum thin-film resistance thermometers painted on machinable ceramic substrates and are manufactured and calibrated by ATK-GASL. Since the run times of HyPulse are on the order of a few milliseconds of established flow, the test article remains at nearly room temperature and visualizations of the combustor flow through uncooled windows are obtained. The integrated optical system ${ }^{8}$ at HyPulse includes a high-speed four-frame sequential schlieren system, a laser holographic interferometer, a laserbased fuel plume planar imaging system, and a path-integrated water vapor measurement.

\section{Operation}

A shock wave generated by the sudden rupture of a double diaphragm separating the high-pressure cold helium driver from the lower-pressure shock tube gas initiates the operation of a test. In detonation drive mode, this initial driven shock passes into the detonable mixture that produces a stronger shock to heat and compress the test gas in the shock tube. The test chamber contains the facility nozzle and the scramjet test hardware. In RST mode, the reflection of the incident shock at the shock-tube-nozzle interface produces the nozzle plenum conditions of a near stagnation state. In the SET mode, the test gas flow is processed by the passage of the incident shock and then 
accelerated by an unsteady expansion fan to a steady flow at the tube exit, achieving an increase in enthalpy through the addition of kinetic energy, without stagnating. The operational envelopes of the HyPulse shock tunnel simulation for both RST and SET modes are presented in Figure 3. The range of dynamic pressure between 600 and $2000 \mathrm{psf}$ ( $\sim 30$ to $100 \mathrm{kPa}$ ) cover the generally accepted air-breathing flight corridor, which is indicated on the figure. Test points for the scramjet tests supporting the Hyper-X scramjet tests at Mach 7 and 10 are indicated. Additional details and descriptions of HyPulse operation are in the literature. ${ }^{5,6,7}$

\section{RST Test Condition}

In the evaluation tests of the X-43 Mach 10 engine flowpath with the HSM, HyPulse was operated as a reflectedshock tunnel. The test gas in the shock tube section had an initial composition of 24 mol- $\% \mathrm{O}_{2}, 75 \mathrm{~mol}-\% \mathrm{~N}_{2}$, and 1 mol- $\%$ Ar. This mixture was used in place of standard dry air to replenish the $\mathrm{O}_{2}$ lost by the formation of NO in the stagnation of the test gas by the reflected shock. This shock-heated mixture yields a test gas that contains the desired amount of about $21 \mathrm{~mol}-\% \mathrm{O}_{2}$, and about 6 mol- $\%$ NO. The CFD solutions of the flow expansion through the nozzle from the plenum condition indicated that the test gas was chemically frozen a short distance downstream of the throat. Test conditions in the plenum were derived from the incident shock speed $U_{\mathrm{s} 1}$ at the end of the shock tube and the measured pressure $\mathrm{P}_{5}$ behind the reflected shock at the shock tube-nozzle interface, as illustrated in Figure 4. When operation is initiated, the high-pressure helium drives a shock-induced detonation wave at the Chapman-Jouget speed, which subsequently drives the incident shock at a speed $\mathrm{U}_{\mathrm{s} 1}$ into the test gas at initial pressure $P_{1}$ and temperature $T_{1}$. The shock speeds, which were detected by pressure sensors along the tube lengths, were consistent from run-to-run. The values plotted in Figure 4 are typical of the average of entry 8 tests values and had a run-to-run variation of less than one percent. The detonation wave speed was the theoretical Chapman-Jouget speed for the detonable mixture; however, the incident shock speed decayed nonlinearly to the nozzle interface, and was fit with a $2^{\text {nd }}$ order polynomial as shown in the figure. Upon reflection the shock further compressed and heated the test gas to near stagnation conditions at $\mathrm{P}_{\mathrm{pln}}=\mathrm{P}_{5}$ and the test gas began to flow through the nozzle. The stagnation enthalpy and equilibrium composition were derived from $P_{1}$ and $T_{1}$, the incident shock speed evaluated at the tube end, and $\mathrm{P}_{5}$, using a series of thermodynamic routines. The thermodynamic calculations also provided conditions at the specified nozzle throat diameter and a one-dimensional estimate of the nozzle exit flow conditions.

\section{Nozzle Calibration}

In RST mode, HyPulse used an axisymmetric contoured nozzle that expanded the shock-heated test gas from the plenum state through an area ratio of 225 (AR-225). The nozzle was designed for a Mach 10 stagnation enthalpy to deliver a local Mach number at the exit that matched the value on the HXRV forebody at the target Mach 10 flight condition, as indicated in Figure 1. Each of the test conditions was confirmed by the acquisition of pitot pressure profiles of the nozzle exit flow. A photograph of the pitot rakes installed at the nozzle exit is given in Figure 5. The facility-rake probes were spaced $2.54 \mathrm{~cm}$ and had conical tips, with piezoelectric pressure transducers close-coupled to reduce response time. The smaller shock-tube rake, shown inset in Figure 5, was originally built to survey the 15$\mathrm{cm}$ diameter tube exit flow, and had probes spaced $1.27 \mathrm{~cm}$ in orthogonal rows. Nozzle calibration results for a typical Mach 10 test case are presented in Figure 6. The pitot pressures from the facility rake only, are normalized by the plenum pressure. Included in the figure are the results for three computations of the nozzle flow. The CFD methods all started at the derived plenum (stagnation) conditions of the test facility and used a finite rate chemistry air model to compute the nozzle flow. Results of the CFD agree well with the measured pitot data in the core flow. The results with the GASP ${ }^{9}$ computer code tend to predict a thicker viscous layer, although core values are in good agreement. The other solutions were obtained from the VULCAN ${ }^{10}$ code. One VULCAN solution, denoted by the broken line, was for a higher pressure condition and the other, denoted by the ' $x$ ' symbol, was at the baseline pressure condition, but at a higher stagnation enthalpy duplicating a flight Mach of about 10.3.

\section{HyPulse Scramjet Model (HSM)}

\section{Test Hardware}

During the course of the ground tests supporting the Hyper-X Mach 10 scramjet engine flowpath development, the test technique and test hardware evolved from the initial Keel Line 6 flowpath (M10-KL6) to the final Mach 10 Keel Line 8 (M10-KL8). Some details of the test history are presented in Table 1. This Mach 10 test program spanned five test entries from mid 1999 through early 2003, but only results for entry 8 are presented here. The test hardware, named the HyPulse Scramjet Model (HSM), was a full-scale height, partial-width replica of the Hyper-X Research Vehicle (HXRV) propulsion flowpath, with the forebody and aft body (nozzle) truncated to achieve a model size compatible with the facility limitations. The HSM had an internal width of about $16.8 \mathrm{~cm}$ (6.6-in.), with 
an overall length of about $180 \mathrm{~cm}$ (70-in). A sketch of the section of the HXRV replicated by the HSM is illustrated in Figure 1. The planar fore-body on the HSM represents the ramp of the M10 HXRV provided flexibility to parametrically vary the conditions at the engine cowl plane. This simulation makes the HSM tests semi-direct connect, since the exact flow structure at the inlet is not identical to flight; however, the goal of the test was to achieve appropriate simulation of the HXRV combustor operation. A boundary-layer trip strip, designed for the specific test conditions in HyPulse, ${ }^{11}$ was placed on the forebody to transition the boundary layer.

Table 1. The Hyper-X Mach 10 engine flowpath model tests.

\begin{tabular}{|c|c|c|c|c|c|c|c|c|c|c|}
\hline \multicolumn{2}{|c|}{ Test Entry } & \multicolumn{4}{|c|}{ HyPulse facility operation } & \multicolumn{5}{|c|}{ HyPulse Scramjet Model Tests } \\
\hline No. & $\begin{array}{l}\text { Test } \\
\text { period }\end{array}$ & $\begin{array}{c}\text { Nozzle } \\
\text { Area } \\
\text { Ratio }\end{array}$ & $\begin{array}{l}\text { Flight } \\
\text { Mach }\end{array}$ & $\begin{array}{l}\text { Stagnation } \\
\text { Pressure } \\
\text { (atm.) }\end{array}$ & $\begin{array}{c}\text { Nozzle } \\
\text { Exit } \\
\text { Mach }\end{array}$ & $\begin{array}{c}\text { Hyper-X } \\
\text { Flowpath } \\
\text { Simulation }\end{array}$ & $\begin{array}{l}\text { Calibrat } \\
\text { ion } \\
\text { runs }\end{array}$ & $\begin{array}{l}\text { Unfueled } \\
\text { Runs } \\
\text { (Tare) }\end{array}$ & $\begin{array}{l}\text { Fueled } \\
\text { Runs } \\
\text { (piloted) }\end{array}$ & $\begin{array}{c}\text { Fueled } \\
\text { Runs } \\
\text { (H2) }\end{array}$ \\
\hline 1 & $\begin{array}{l}11 / 16 / 98- \\
01 / 26 / 99\end{array}$ & 175 & 7 & 49., 98., 146. & 7.2 & M7-KL6 & 16 & 3 & 18 & 6 \\
\hline 2 & $\begin{array}{l}01 / 27 / 99- \\
02 / 17 / 99\end{array}$ & 175 & 10 & 82., 146. & 6.4 & M7-KL6 & 4 & 2 & 5 & 1 \\
\hline $3 \& 4$ & $\begin{array}{l}07 / 01 / 99- \\
03 / 08 / 00\end{array}$ & 175 & 10 & 218 & 6.4 & M10-KL6 & 5 & 4 & 11 & 21 \\
\hline 5 & $\begin{array}{l}05 / 24 / 00- \\
10 / 13 / 00\end{array}$ & 225 & 10 & 228 & 6.8 & M10-KL6 & 8 & 4 & 15 & 10 \\
\hline \multirow{2}{*}{7} & \multirow{2}{*}{$\begin{array}{c}07 / 05 / 01- \\
11 / 09 / 01\end{array}$} & \multirow{2}{*}{225} & 9 & \multirow{2}{*}{228} & 7.2 & \multirow{2}{*}{ M10-KL8 } & 3 & 1 & 2 & 4 \\
\hline & & & 10 & & 6.8 & & 4 & 3 & 9 & 9 \\
\hline \multirow{2}{*}{8} & \multirow{2}{*}{$\begin{array}{c}10 / 07 / 02- \\
03 / 18 / 03\end{array}$} & \multirow{2}{*}{225} & 10 & 228., 289 & 6.8 & \multirow{2}{*}{ M10-KL8 } & 1 & 5 & 11 & 7 \\
\hline & & & 10.3 & 228 & 6.7 & & 1 & 0 & 3 & 2 \\
\hline
\end{tabular}

Notes: Entries 1 \& 2 were with Mach 7 HXRV flowpath; Facility shakedown and calibration Entry 6 (not listed) tested HSM with M10-KL6 geometry at flight Mach 15 condition;

Piloted fueled runs used $5 \%$ silane in hydogen fuel mixture (SFM) for $1 \& 2$; usually $2 \%$ SFM for others

Photographs of the HSM hardware mounted cowl-side up in the HyPulse test chamber are presented in Figure 7. The boundary-layer trips and a single pitot probe, mounted at the forebody leading edge (FBLE) axial location, are indicated in the photo. The engine isolator/combustor section had windows to permit optical access for schlieren and other optical diagnostics that were acquired in some tests through the $40 \mathrm{~cm}$ (16-inch) diameter windows in the test chamber. Instrumentation on the model consisted of piezoelectric transducers and thin-film thermocouples for heat-flux data on the body side and cowl side surfaces. The measurement locations of the HXRV engine flowpath were replicated (if possible) and others were added to provide better spatial resolution of the pressures in the combustor and nozzle sections. In total, the body-side surface accommodated 143 measurements, but only about 80 were used for pressures during the tests. On the cowl side surface, 43 of 69 measurement locations were used.

During the course of the test entries and the concurrent CFD-based analyses, it became evident that the HSM hardware was not providing an adequate replication of the flow structure entering the combustor. This deficiency was primarily due to the lack of true duplication of the HXRV forebody shock system at the cowl-leading edge by the leading-edge shock of the HSM fore body. Consequently, the inlet shock train was misplaced at the inlet isolator section at the start of the combustor. Although the integral, flux-averaged properties (P, T, V, and M) at the CLE and in the inlet isolator were in good agreement between the target flight and HSM test conditions, detailed CFD analyses indicated that the flow profiles were not. To better replicate the CFD predicted shock position for the HXRV, the cowl on the HSM was moved aft (by a few $\mathrm{cm}$ ) based on CFD analyses of the HSM for the baseline HyPulse test conditions. As subsequently discussed, the operation of the HSM with the cowl moved aft provided a better simulation when compared with flight operation. This result raised the awareness that at hypervelocity conditions, that the non-uniform, shock-dominated flow entering a scramjet in flight also needs to be replicated in the ground test technique. 


\section{HSM Calibration}

To obtain further assurance about the test flow captured by the HSM test hardware, flow surveys were conducted using a pair of custom made pitot pressure rakes mounted near the CLE. Pitot pressure profiles are shown with a CFD comparison in Figure 8. The two pitot rakes, with probes vertically spaced $0.5 \mathrm{~cm}$ are shown in the inset photo. The rakes are about $7.32 \mathrm{~cm}$ apart, with one aligned with the forebody centerline, and mounted perpendicular to the forebody surface at a location about $10 \mathrm{~cm}$ upstream of the CLE. In general, the pitot data and CFD solution agree in the boundary layer size and the location of the shock from the HSM FBLE, as indicated by inflection near the $11-\mathrm{cm}$ position above the surface. In the region of interest, the general level of agreement between the CFD and the data at the baseline Mach 10 enthalpy is acceptable.

\section{Review of the Test Results}

\section{A. Test Conduct}

Evaluation tests of the M10-KL8 propulsion flowpath were conducted during entry 8 of the HSM hardware at the nominal conditions listed in Table 2. Tests with variations of the test condition and HSM mounting and cowl position, designated by Test Types $\mathrm{A}$ through $\mathrm{E}$ in Table 2, were conducted over a range of equivalence ratios to evaluate the operation at the target flight condition and at some off-design points. The Type A tests was a series to complete the previous test entry with a full cowl on the HSM. For the remaining tests, the cowl was moved aft as previously discussed. In Type C, HyPulse was operated at higher stagnation enthalpy to provide a Mach 10.3 duplication; for test Types D \& E HyPulse operation was modified to increase the plenum pressure by about 20 percent at the baseline Mach 10 enthalpy of test Type A \& B. Table 2 also gives nominal conditions in the core flow of the nozzle exit that were extracted from CFD solutions starting at the facility plenum conditions.

The usual test procedure for each test type was to run a matrix of up to seven runs that included a reference conditions without fuel injection, referred to as a "tare" case, three runs with a fuel mixture of two percent silane in hydrogen, and three runs with pure hydrogen. The three runs with each fuel were at nominal fuel equivalence ratios of 1.2, 0.8, and 1.6, based on the $\mathrm{O}_{2}$ fraction in the test gas. Silane $\left(\mathrm{SiH}_{4}\right)$ a pyrophoric gas, has long been used in scramjet ground tests to promote ignition and serves as a pilot in the short duration tests of the shock tunnel environment. The HXRV includes silane-hydrogen piloted operation during the initial fueling sequence before transitioning to all hydrogen. In all cases of the HSM tests, the use of the silane-fuel mixture (SFM) provided the most reliable operation.

Table 2. Nominal test conditions for the HSM

\begin{tabular}{|c|c|c|c|c|c|c|c|c|c|c|c|c|c|c|}
\hline \multicolumn{5}{|c|}{ Reference HyPulse Operation } & \multicolumn{8}{|c|}{ Facility Nozzle Exit (Core flow) } & \multicolumn{2}{|c|}{ HSM Position } \\
\hline \multirow[t]{2}{*}{$\begin{array}{l}\text { TEST } \\
\text { TYPE }\end{array}$} & \multirow[t]{2}{*}{$\begin{array}{c}T_{t} \\
(K)[R]\end{array}$} & \multirow[t]{2}{*}{$\begin{array}{l}\mathrm{H}_{\mathrm{t}} \quad(@ 0 \\
\mathrm{K})(\mathrm{MJ} / \mathrm{kg}) \\
\text { [Btu/lb] }\end{array}$} & \multirow[t]{2}{*}{$\begin{array}{c}P_{\mathrm{pln}} \\
(\mathrm{atm})\end{array}$} & \multirow[t]{2}{*}{$\begin{array}{l}\text { Effec } \\
\text { Flight } \\
\text { Mach }^{\dagger}\end{array}$} & \multirow[t]{2}{*}{ Mach } & \multirow[t]{2}{*}{$\begin{array}{c}P_{n e} \\
(k P a) \\
{[p s i a]}\end{array}$} & \multirow[t]{2}{*}{$\begin{array}{c}T_{\text {ne }} \\
(\mathrm{K})[\mathrm{R}]\end{array}$} & \multirow[t]{2}{*}{$\begin{array}{c}V_{\text {ne }} \\
(\mathrm{m} / \mathrm{s}) \\
{[\mathrm{fps}]}\end{array}$} & \multicolumn{4}{|c|}{$\begin{array}{l}\text { Composition } \\
\text { (mole fraction) }\end{array}$} & \multirow{2}{*}{$\begin{array}{l}\text { Flow } \\
\text { angle* } \\
\text { (deg) }\end{array}$} & \multirow[t]{2}{*}{ Cowl } \\
\hline & & & & & & & & & $\mathrm{N}_{2}$ & $\mathrm{O}_{2}$ & NO & $\mathrm{Ar}$ & & \\
\hline A & 3720 & 4.92 & 224 & 9.97 & 6.82 & 2.99 & 466 & 2936 & 0.7164 & 0.2055 & 0.0648 & 0.013 & 1 & Full \\
\hline B & {$[6696]$} & {$[2115]$} & & & & [0.433] & [839] & [9633] & & & & & 1 & Aft \\
\hline C & 3922 & 5.32 & 230 & 10.39 & 6.78 & 3.11 & 513 & 3053 & 0.7248 & 0.2146 & 0.050 & 0.010 & 1 & Aft \\
\hline & {$[7060]$} & {$[2287]$} & & & & {$[0.451]$} & [923] & [10016] & & & & & & \\
\hline D & 3679 & 4.82 & 281 & 9.86 & 6.97 & 3.46 & 440 & 2914 & 0.726 & 0.2157 & 0.0479 & 0.010 & 1 & Aft \\
\hline$E$ & [6622] & [2072] & & & & [0.502] & [792] & [9560] & & & & & 0 & Aft \\
\hline
\end{tabular}

$\dagger$ Effective flight Mach is derived from the test stagnation enthalpy, assuming sound speed is $305 \mathrm{~m} / \mathrm{s}$

* Flow angle is the angle of the HSM forebody to the nozzle exit flow

‡ Cowl position was moved aft to better replicate inlet shock train expected at flight condition. 


\section{B. Hyper-X Flight Data Comparisons}

The successful launch and free flight of the X-43 in November 2004 provided about ten seconds of fuel-on powered data at near Mach 10 conditions. This quantity of data is about 50 times that obtained in Mach 10 tests of the M10-KL8 flowpath of the HSM in HyPulse. The pressure data internal to the engine flowpath from the CLE to the CTE were extracted at specific times where the flight parameters ( $Q$ and $\alpha$ ) were level and fueling values were stable. In making the direct comparisons between the ground test and flight, there are certain simulation differences that are not directly accountable. Differences in the chemical composition of the test gas and atmospheric air, the bulk energy split between thermal and kinetic in the two streams is different due to surface heating, and the flow shock structures. However, an attempt was made to scale the ground test data to the flight condition by using the mass flux at the CLE. For each set of selected ground test data, the procedure was to scale the pressures by the plenum pressure to a baseline condition, for which CFD details were known. Then, for the specific fuel equivalence ratio, the data were re-scaled by the mass flux ratio from the baseline test case to flight.

\section{Tare (unfueled) data.}

Comparisons between the ground test and flight pressure data on the cowl and body sides are presented in Figure 9 for the tare runs (without fuel injection). The data are plotted as the scaled pressure value along the length of the internal flow path. For this comparison, data are for HSM test types A, B, D \& E (identified in Table 2) that are all about the same stagnation enthalpy. All test types except A have the cowl moved aft, types D \& $\mathrm{E}$ have higher plenum pressure, and for type $\mathrm{E}$ the HSM is at $0^{\circ}$. The effect of the cowl in the aft position is evident from the data on the body side pressure distributions for test type A, which shows a pressure rise as a result of the cowl-leading edge shock impingement point location upstream of the others. However, the pressure distributions in the inletisolator region are all about the same level on the body side. The data from the X-43 flight 3 show very good agreement with the HSM data, particularly on body side.

\section{Fueled data comparisons.}

Comparisons of the HSM test data and the X-43 flight results are presented in Figure 10 for piloted fuel injection at a nominal equivalence ratio of about 1.25 . The piloted fuel was a mixture of $2 \%$ silane in hydrogen in the HSM tests. The fueling sequence in the X-43 engine was designed to deliver the same mixture to the fuel injector manifolds. Data are presented from the HSM for test types A, B, C, and E (see Table 2). The scaled data for the various HSM tests in the inlet-isolator section show good agreement with each other and with the flight data, with differences noted for test type A with the full cowl and for type E with the HSM forebody at $0^{\circ}$. In the combustor, the X-43 flight data show noticeably higher pressure, suggesting more robust ignition and combustion than occurred in the ground tests. This result was not totally unexpected, since the HSM testing was with a test article at room temperature and lasted only a few milliseconds; whereas in the flight test, the internal surfaces were exposed to the Mach 10 flow for about five seconds after the cowl opened before the fuel injection started. However, the HSM data with silane piloted fuel are in generally good agreement with the X-43 data. The pressure comparisons in the nozzle expansion show good agreement, except near the initial expansion. These lower values at the start of the nozzle expansion in the HSM data were consistent from run-to-run and may be a result of chemical kinetics in the less robust combustion in the ground test environment. This effect has yet to be adequately investigated.

A comparison of the HSM and X-43 flight data for the case with hydrogen fuel at an equivalence ratio of about 1.30 is presented in Figure 11. The HSM data in the inlet and isolator section again show good agreement with the flight data and confirm the run-to-run repeatability of the HyPulse HSM test technique. For comparison, this figure includes the data for silane piloted operation (Figure 10). The HSM pressures with hydrogen fuel are less than those with silane piloted fuel, as expected. However, the X-43 flight data with hydrogen fuel show slightly higher levels than were obtained for the piloted fuel. This result clearly suggests that the flight engine is operating well, once combustion was initiated with the silane-hydrogen fuel mixture. Although not shown, the flight data continued to show robust combustion throughout the fueling sequence as the hydrogen fuel equivalence ratio decreased. The lower pressure values in the ground test without the silane piloted fuel are a consequence of the test environment in pulse facilities, where the hardware stays cold, and the test duration does not allow for any aero-heating of the surfaces as would occur in flight. However, the upside of this issue is that the use of shock tunnels has now been well confirmed as a productive test environment for airbreathing engine concepts into the hypervelocity regime, with the caution that a piloted fuel or other ignition aid may be needed with small scale test articles at low pressure. 


\section{Concluding Remarks}

The paper has presented a brief review of the ground test program conducted in the HyPulse reflected shock tunnel that supported the development and evaluation of the scramjet engine flowpath for the Mach 10 Hyper-X Research Vehicle (HXRV). These tests covered a range of potential flight conditions and in combination with computational analyses, led to changes in the engine flowpath that was flown. In addition, these data expanded the database for scramjet operation into the hypervelocity flight regime, and provided confirmation for a scramjet design method that was based on the Mach 7 scramjet database. Comparisons of the ground test data with selected data from the successful flight of the HXRV (or X-43) that flew at nearly Mach 10 in November 2004 were presented and show good agreement for HyPulse test runs in which the hydrogen fuel was augmented with silane to prompt ignition and combustion. Comparisons of tare data acquired without fueling the flow in both ground test and flight operation also exhibit very good agreement, confirming that scramjet testing in the millisecond time scale available in shock tunnels does provide meaningful data, thereby expanding the ground test regime for hypersonic airbreathing propulsion concepts.

\section{Acknowledgments}

The authors acknowledge with gratitude the skills and competence of the HyPulse test team, led by Dr. Ching-Yi Tsai, at the GASL Division of ATK in Ronkonkoma, NY, for their innovative and creative conduct of the scramjet tests, the data acquisition and processing, and technical collaboration over the years of the Hyper-X Program. In addition, the hardware design and fabrication staff at ATK-GASL was indispensable in making facility nozzles and the test hardware. It would not have been possible without the entire team.

\section{References}

${ }^{1}$ Anderson, G. Y.: An outlook on Hypersonic Flight. AIAA Paper No. 87-2074, June 1987.

${ }^{2}$ Rogers, R. C.; Capriotti, D. P.; and Guy, R. W.: Experimental Supersonic Combustion Research at NASA Langley. AIAA Paper No. 98-2506, June 1998.

${ }^{3}$ Curran, E. T.: Scramjet Engines: The First Forty Years. ISABE Paper No. 97-7005, XIII ISABE, September 1997.

${ }^{4}$ McClinton, et al. Hyper-X Wind Tunnel Program. AIAA 98-0553. January 1998.

${ }^{5}$ Chue, R.S.M., et al: NASA's HYPULSE Facility at GASL-A Dual Mode, Dual Driver, ReflectedShock/Expansion Tunnel. In Advanced Hypersonic Test Facilities. Chap. 3, pp 29-72; Edited by F. K. Lu \& D. E. Marren; Prog. In Astron. \& Aeron. Vol 198, 2002.

${ }^{6}$ Guy, R. W.; Rogers, R. C.; Puster, R. L.: Rock, K. E.; and Diskin, G. S.: The NASA Langley Scramjet Test Complex. AIAA Paper 96-3243, July 1996.

${ }^{7}$ Roffe, G.; Bakos, R.; Erdos, J.; Swartwout, W.: The Propulsion Test Complex at GASL. ISABE Paper 97 7096, Sep. 1997.

${ }^{8}$ Tsai, C.Y.; and Bakos, R. J.: Shock Tunnel Flow Visualization with a High Speed Schlieren and laser Holographic Interferometry System. AIAA Paper 98-2700, June 1998.

${ }^{9}$ Aerosoft, Inc., GASP (General Aerodynamic Simulation Program, Computational Flow Analysis Software for the Scientists and Engineer) Version 4, 2000.

${ }^{10}$ White, J. A., and Morrison, J. H.: A Pseudo-Temporal Multi-Grid Relaxation Scheme for Solving the Parabolized Navier-Stokes Equations (VULCAN code). AIAA Paper 99-3360, June 1999.

${ }^{11}$ Berry, S. A.; Auslender, A. H.; Dilley, A. D.; and Calleja, J. F.: Hypersonic Boundary-Layer Trip Development for Hyper-X. Journal of Spacecraft and Rockets, Vol. 38, No. 6, 2001, pp.853-864. 


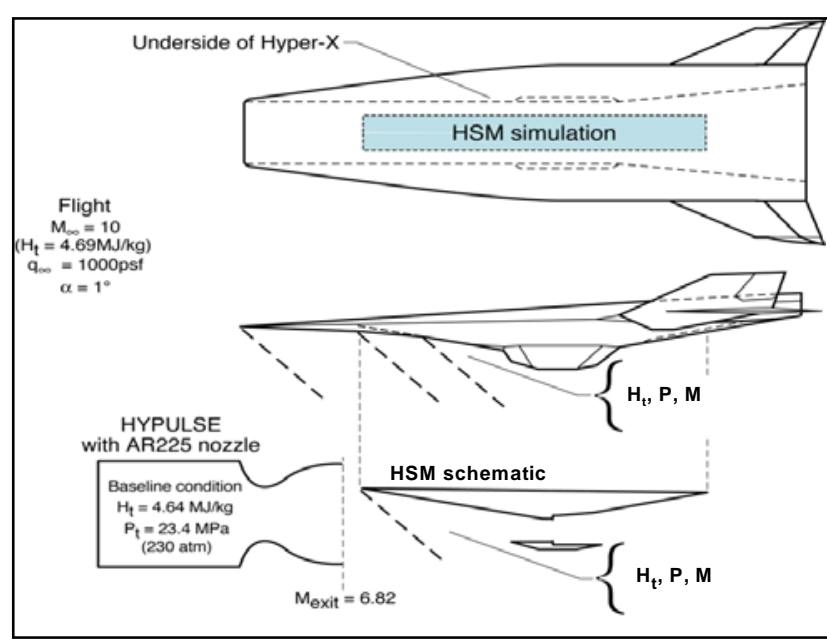

Figure 1. Aero-propulsion simulation in ground test facilities.

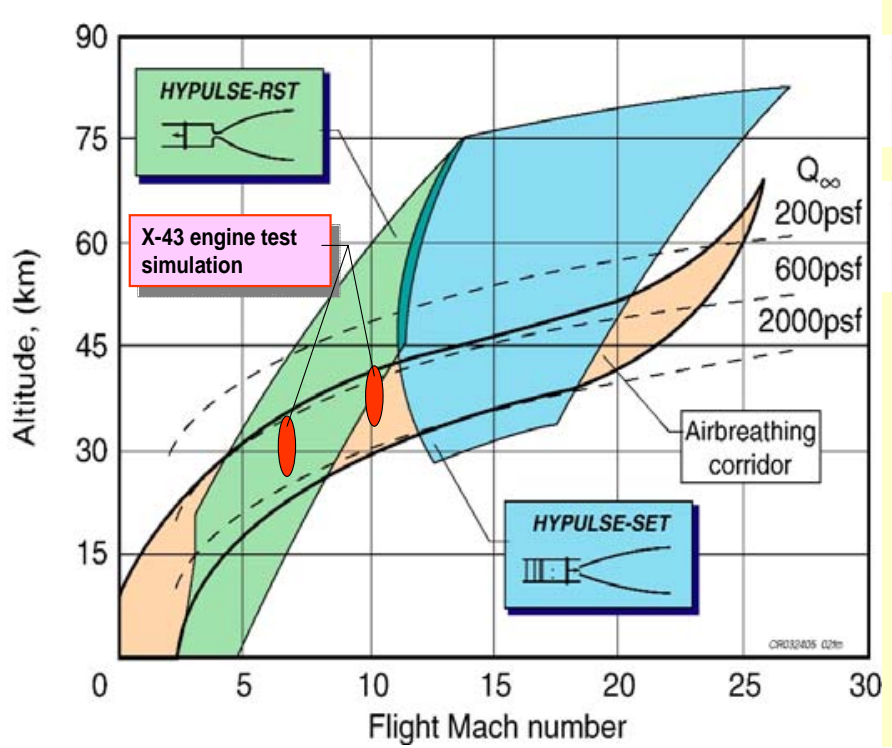

Figure 3. HyPulse test envelope.

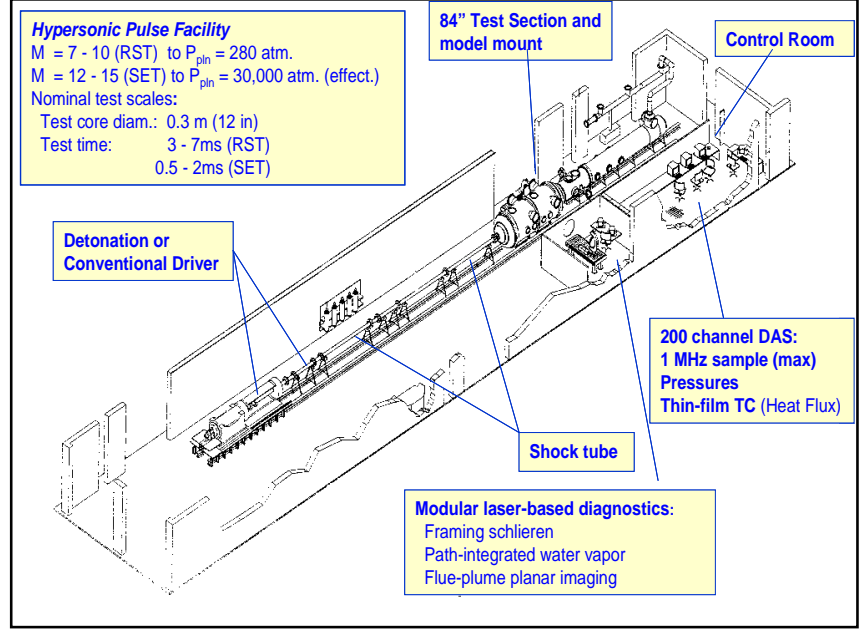

Figure 2. The NASA HyPulse Shock Tunnel.
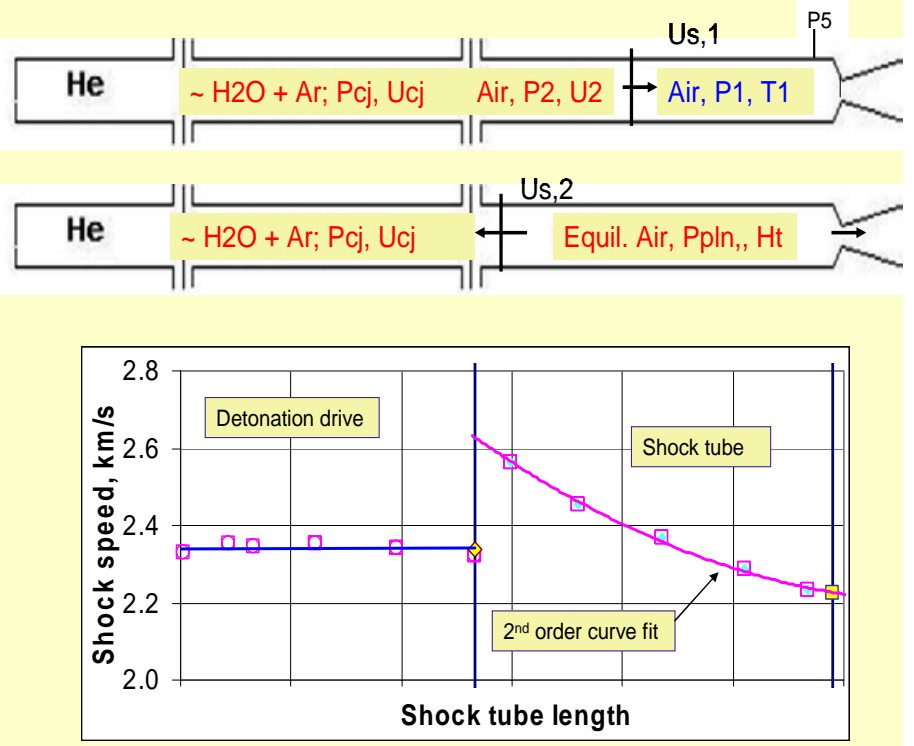

Figure 4. Derivation of HyPulse test conditions. 


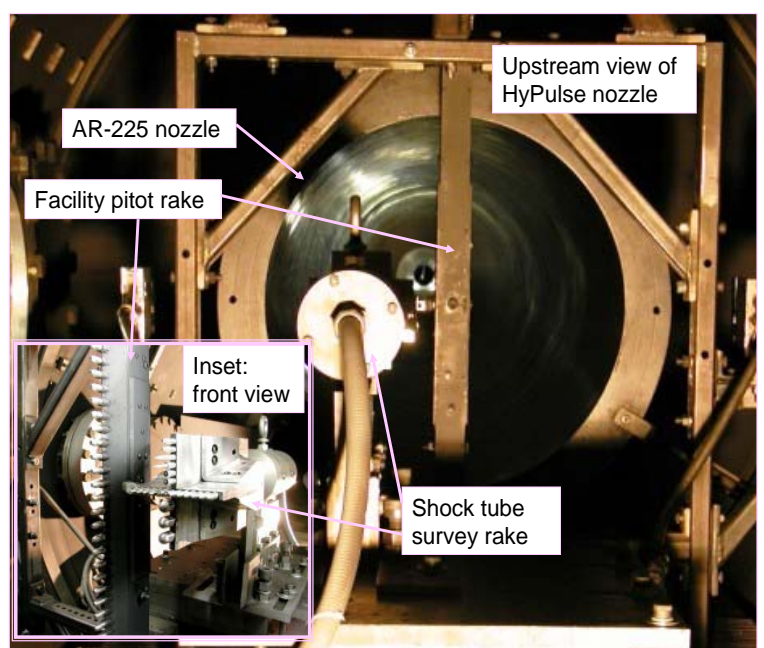

Figure 5. Photograph of the HyPulse nozzle facility rake and shock tube rake.

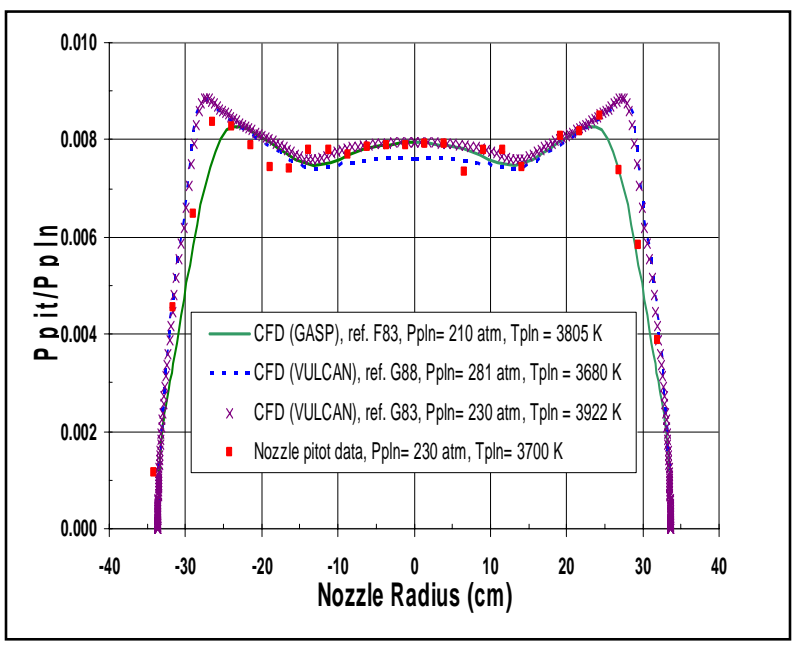

Figure 6. Nozzle exit pitot profile with CFD comparisons.

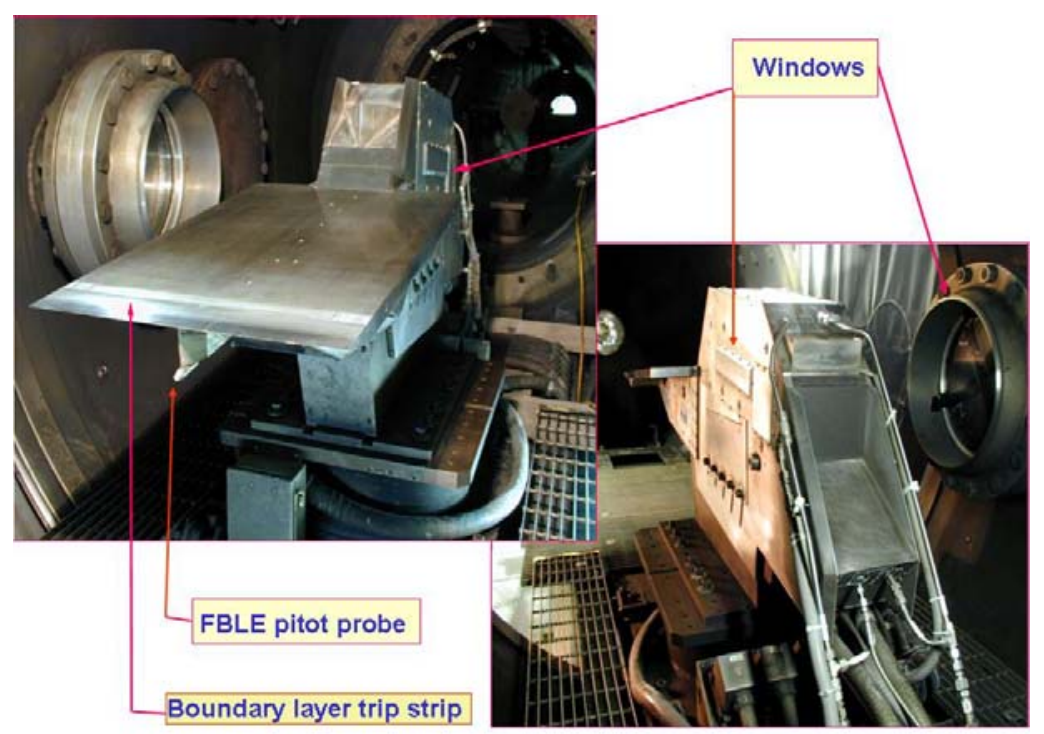

Figure 7. The HyPulse Scramjet Model (HSM) in the test chamber

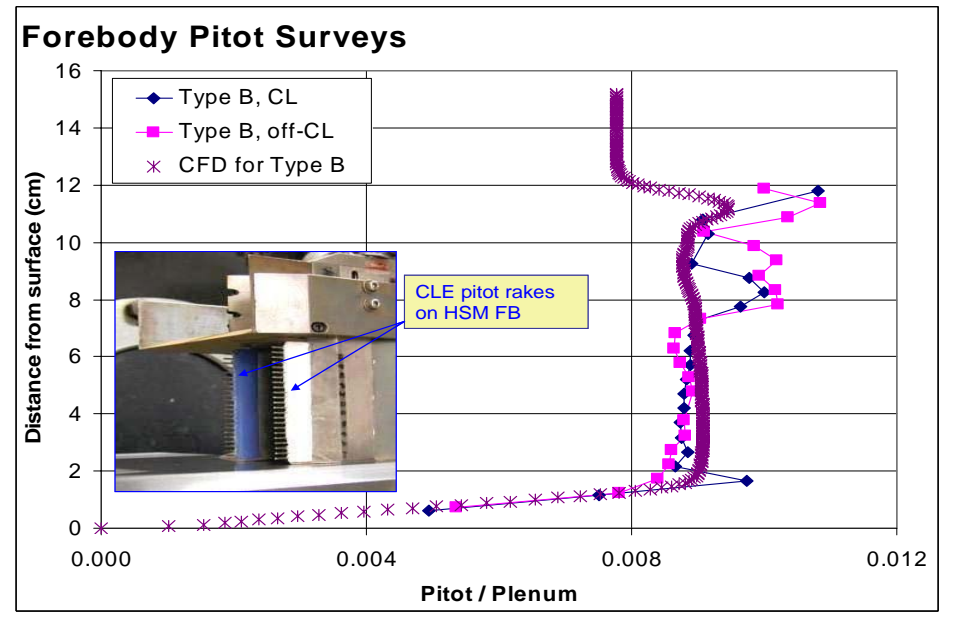

Figure 8. Pitot pressure profile on the HSM forebody, with CFD comparisons.

American Institute of Aeronautics and Astronautics 

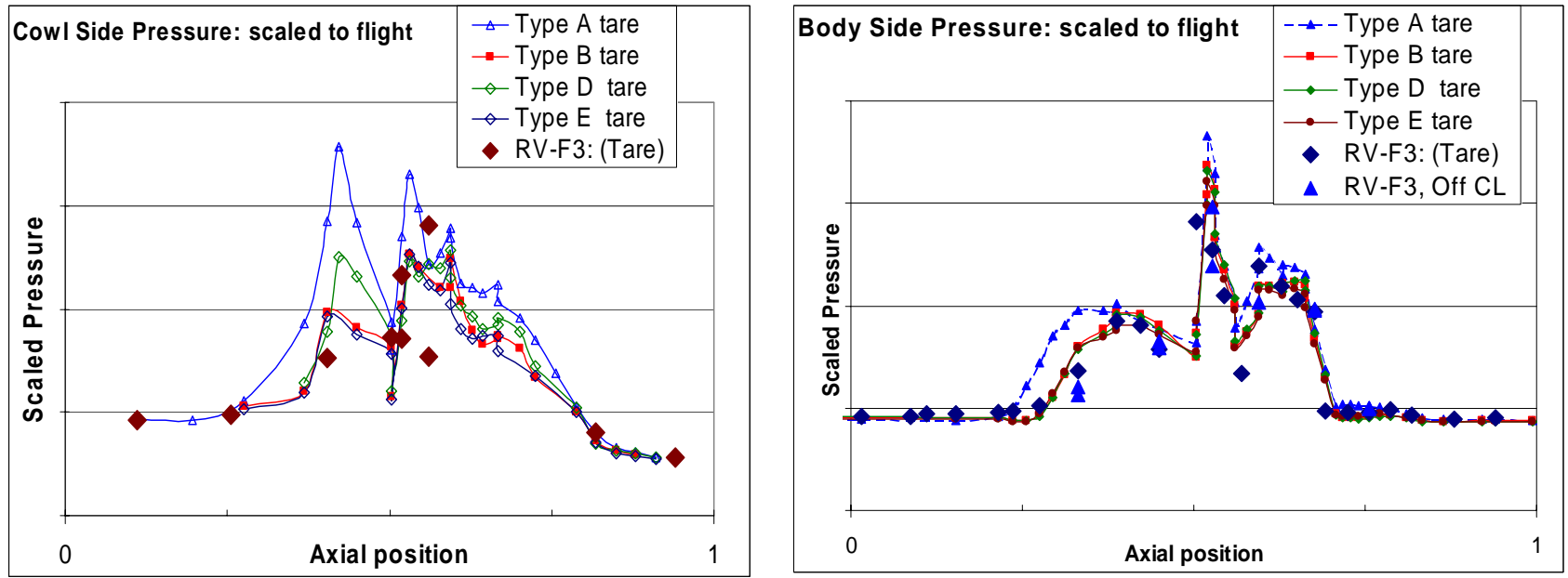

Figure 9. Comparison of ground test and flight pressure distribution, no fuel injection.
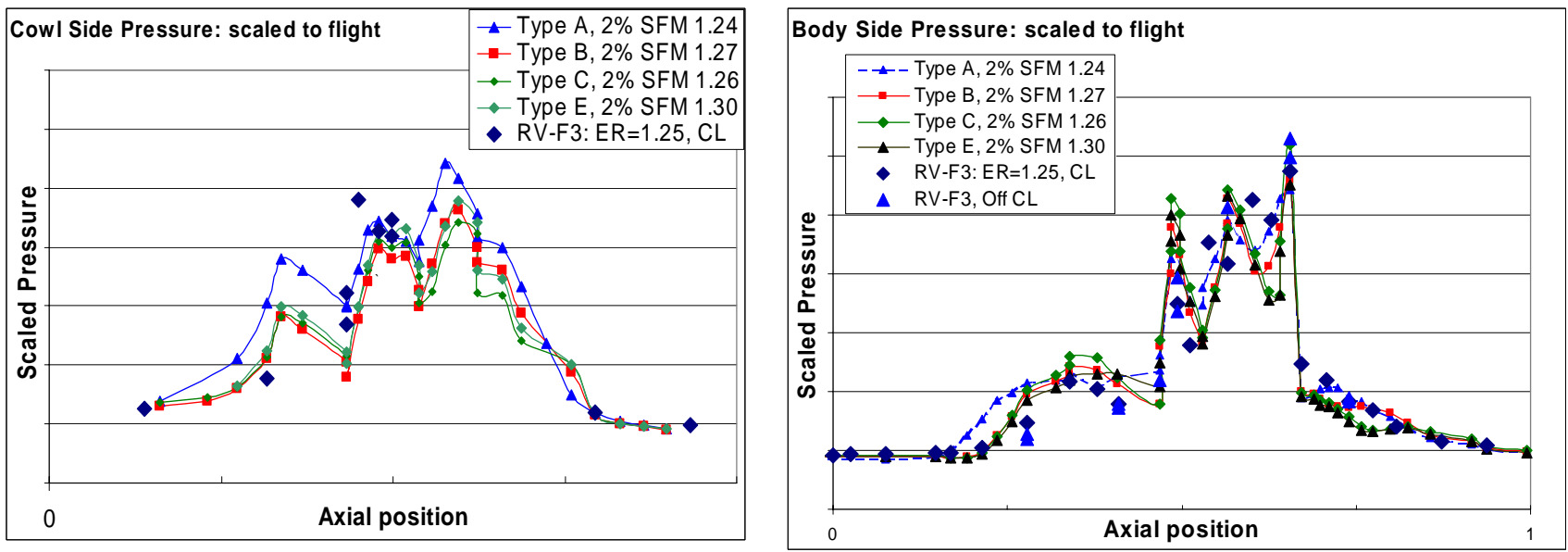

Figure 10. Comparison of ground test and flight pressure distributions, piloted fuel injection.
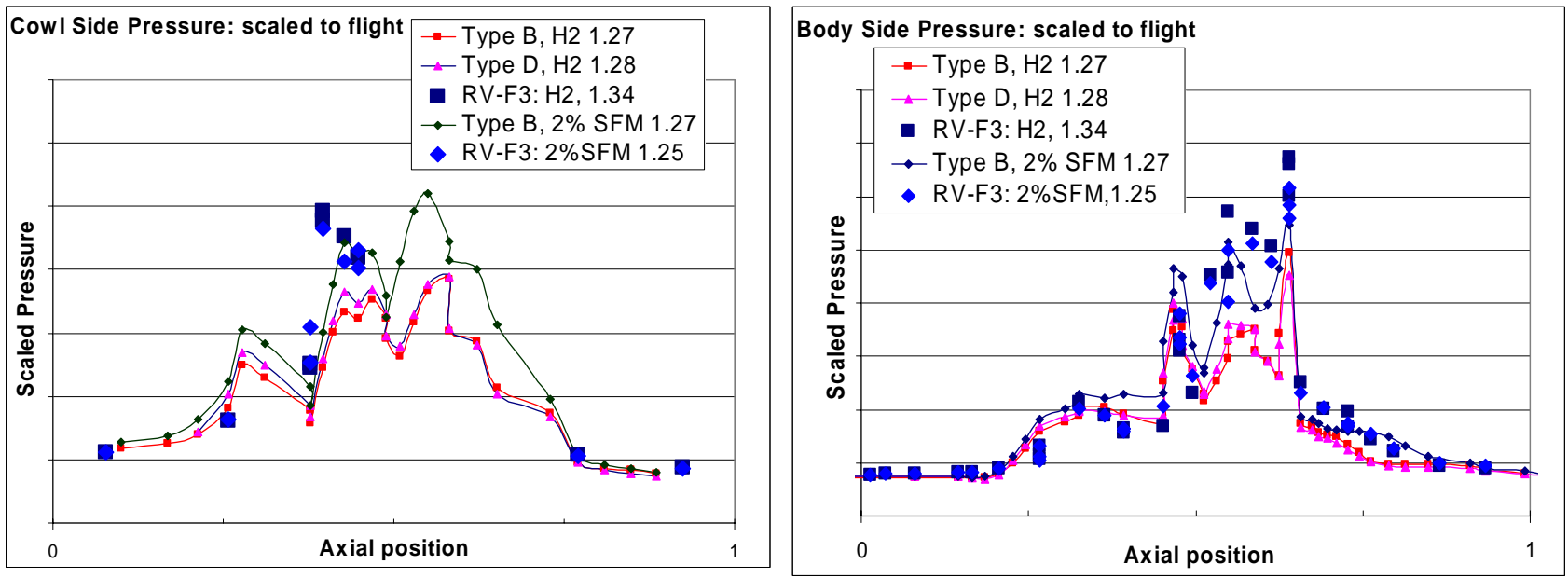

Figure 11. Comparison of ground test and flight pressure distributions, hydrogen fuel injection. 